\title{
Vitamin D Metabolic Profiles in Premenopausal Women Wearing Niqab and Hijab in Sunny Basrah
}

\author{
Samih A. Odhaib ${ }^{1}$, Nassar T. Alibrahim ${ }^{1}$, Ibraheem A. Zaboon ${ }^{1}$, Abbas A. Mansour ${ }^{1}$ \\ 1. Adult Endocrinology, Faiha Specialized Diabetes, Endocrine and Metabolism Center (FDEMC) College of Medicine, \\ University of Basrah, Basrah, IRQ
}

Corresponding author: Samih A. Odhaib, samihabedodhaib@gmail.com

\section{Abstract \\ Background}

Conservative clothing like niqab and hijab may affect the wearer's vitamin D metabolic parameters even in predominantly sunny areas of the world (i.e., areas with adequate sunlight exposure throughout the year). Our objective was to evaluate the effect of wearing the niqab or hijab on different vitamin D3 metabolic parameters in a sample of premenopausal women from Basrah.

\section{Methodology}

This was a cross-sectional observational study on premenopausal women who wore a niqab $(n=64)$, with a comparable age-matched group of women who wore the hijab $(n=60)$. Biochemical evaluation of the vitamin D3 metabolic profile involved 25-hydroxycholecalciferol (25-OH)-vitamin D, corrected serum calcium, parathyroid hormone (PTH), phosphorus, and alkaline phosphatase estimation. Statistical comparison of these parameters was made using the independent sample t-test and Mann-Whitney-U test.

\section{Results}

The two groups of women were age- and weight-matched, with a median age of 39 and median body mass index (BMI) of $31.8 \mathrm{~kg} / \mathrm{m}^{2}$. Overall, age, marital status, and BMI of women in both groups had no significant relationship with the vitamin D3 metabolic parameters (low 25-OH-vitamin D, low corrected calcium, and high PTH). The subgroup analysis for women wearing the niqab showed the same results.

\section{Conclusions}

Wearing niqab or hijab in premenopausal women was not associated with any significant statistical relationship or difference in vitamin D3 metabolic parameters. Conservative dress styles like niqab and hijab are practical barriers to sun exposure and contribute to suboptimal vitamin D levels, affecting subsequent metabolic pathways. Healthcare professionals should advise women who wear niqab or hijab to increase their vitamin D3 levels through culturally appropriate alternative mechanisms.

Review began 04/26/2021 Review ended 05/01/2021 Published 05/08/2021

(c) Copyright 2021 Odhaib et al. This is an open access article distributed under the terms of the Creative Commons Attribution License CC-BY 4.0., which permits unrestricted use, distribution, and reproduction in any medium, provided the original author and source are credited.
Categories: Endocrinology/Diabetes/Metabolism, Family/General Practice, Epidemiology/Public Health Keywords: basrah, calcium, hijab, hypovitaminosis, niqab, parathormone, vitamin d deficiency, dress style

\section{Introduction}

According to religious and cultural norms, conservative Muslim women's dress styles range from dark, solidcolored, whole-body covering, including the hands and face (niqab), to more common styles that exclude the hands and face (hijab), which can be dark or colorful. Women typically wear the niqab or hijab outdoors but not inside their homes [1].

Women wearing a hijab or niqab have insufficient skin surface area for sun exposure. Consequently, they experience less vitamin D3 synthesis compared to women wearing a western-style dress [2-5] because hijab and niqab dress styles attenuate the penetration of ultraviolet B (UVB) light needed for vitamin D3 synthesis $[3,5]$.

The prevalence of hypovitaminosis D is 1.6 to 1.7 times higher for women wearing a hijab and 1.9 to 2.7 times higher for women wearing a niqab than women in western dress styles $[1,6]$. Hypovitaminosis D carries a greater risk of osteoporosis [7].

The main predictors for hypovitaminosis D include increasing age, female gender, multiparity, high body mass index (BMI), low physical activity levels, low intake of calcium or vitamin D supplements, concealed clothing, low sun exposure duration (low UVB doses), winter season, low socioeconomic status, urban residence, skin pigmentation, and chronic comorbidities [8-11]. 
We evaluated the effect of wearing niqab and hijab on the vitamin D status in a sample of Iraqi women from Basrah, Iraq.

The abstract of this article was submitted as an e-poster in the American Association of Clinical Endocrinology Gulf Chapter Virtual Annual Meeting (AACE GC) conducted in November 2020. The abstract was also submitted as an e-poster at the ENDO2021 of the Endocrine Society conducted in March 2021.

\section{Materials And Methods}

We conducted a cross-sectional observational study on premenopausal women who wore the niqab and attended Faiha Specialized Diabetes, Endocrine and Metabolism Center (FDEMC) in Basrah, Iraq, in 2019, for consultation for menstrual irregularities. Women with the niqab who had continued wearing the niqab in the last three years were enrolled initially in the study $(n=64)$.

The study excluded women with a history of chronic comorbidities (e.g., diabetes mellitus, thyroid diseases, adrenal diseases, celiac disease, inflammatory bowel disease, malignancies, and lactose intolerance), pregnancy or lactation in the last three years, current or past history of regular use of hormonal medications (e.g., steroids, antipsychotics, heparin, anti-resorptives, and contraceptive medications), history of recent fractures, history of any skeletal disability or wheel-chair use for any indication, history of any recent operative intervention, and those with regular outdoor work. All the enrolled women were unemployed or did not work away from home for at least three years, with no regular outdoor work.

We evaluated the enrolled women using thorough history-taking, physical examinations, and biochemical investigations. We collected demographic and general characteristics (e.g., age, weight, BMI, and marital status) and assessed 25-hydroxycholecalciferol (25-OH)-vitamin D, corrected serum calcium, phosphorus, and parathyroid hormone (PTH). We also evaluated thyroid hormone levels, alkaline phosphatase (ALP), lactate dehydrogenase, and creatinine phosphokinase for enrollment and exclusion purposes.

We enrolled 64 women who wore the niqab (i.e., the niqab group). Another age-matched 64 women who wore the hijab were selected as a comparison group (i.e., the hijab group or control group), who presented at the same time and met the criteria for patient selection. The randomization in the age-matched hijab group was done on a 1:1 basis. Four women in the hijab group were considered as defaulters and were excluded from the study.

The niqab in Iraq is a black outfit covering the whole body, even the eyes, while the hijab can feature multiple colors and covers the whole body except the face, hands, and (sometimes) feet. Women who wear hijab have $8 \%$ skin exposure, while skin exposure is null for women who wear the niqab [12].

\section{Laboratory investigations}

Study participants underwent an early morning venous sample following a minimum eight-hour overnight fasting. A 10-mL sample of venous blood was collected between 8:00 AM and 10:00 AM and kept in a gel tube, then centrifuged at 4,100 $\mathrm{xg}$ in a NÜVE-NF 800 centrifuge (NÜVE, Ankara, Turkey). The 25-OH-vitamin D and PTH were assessed using the electrochemiluminescence technology of a Cobas e411 Analyzer (Roche, Germany). The reference values for $25-\mathrm{OH}$-vitamin D were $<50 \mathrm{nmol} / \mathrm{L}$ (deficiency), 52 to $70 \mathrm{nmol} / \mathrm{L}$ (insufficient), and $>70$ to $150 \mathrm{nmol} / \mathrm{L}$ (sufficient). The reference range of PTH was 1.5 to $6.5 \mathrm{pmol} / \mathrm{L}$. Serum calcium, albumin, phosphorus, and ALP levels were measured using a Cobas INTEGRA 400 plus analyzer (Roche, Germany). The serum reference ranges were as follows: calcium, 2.1 to $2.6 \mathrm{mmol} / \mathrm{L}$; albumin, 35 to $50 \mathrm{~g} / \mathrm{L}$; ALP, 0.68 to $2.55 \mu \mathrm{kat} / \mathrm{L}$; and phosphorus, 0.99 to $2.02 \mathrm{mmol} / \mathrm{L}$.

\section{Ethical approval and consent}

All women enrolled in the study provided informed verbal and written consent. The study was conducted in accordance with the ethical standards of the FDEMC research committee, from which the ethical approval was obtained, and followed the 1964 Declaration of Helsinki and its later amendments or comparable ethical standards.

\section{Statistical analysis}

We analyzed the data using IBM SPSS Statistics for Windows, version 26.0. (IBM Corp., Armonk, NY). The study used the mean \pm standard deviation or frequency (\%) for data expression. For continuous variables, we used the independent t-test and the Mann-Whitney U-test. Scatter plots were used to demonstrate different relationships between $25-\mathrm{OH}$-vitamin $\mathrm{D}$ and other variables. A two-tailed $\mathrm{p} \leqslant 0.05$ was considered statistically significant at a $95 \%$ confidence interval.

\section{Results}

The vast majority of women who attended FDEMC in 2019 wore the hijab, and a minority wore the niqab. No women wore a western-style dress. 
Table 1 presents demographic information for both groups. The median age was 39 years (age range: 20-50 years), and the mean age and distribution of women across age groups were similar and did not differ significantly. The age of women in both groups had no significant relationship with vitamin D3 metabolic parameters (low 25-OH-vitamin D, high PTH, and low corrected calcium levels).

\begin{tabular}{|c|c|c|c|c|}
\hline \multicolumn{2}{|l|}{ Variables } & Niqab $(n=64)$ & Hijab $(n=60)$ & P-Value \\
\hline \multirow{3}{*}{ Age } & Mean \pm SD years & $39.0 \pm 8.9$ & $38.8 \pm 9.0$ & $0.916^{\mathrm{a}}$ \\
\hline & $\leq 39$ years $\mathrm{n}(\%)$ & $33(51.6)$ & $30(50.0)$ & \multirow{2}{*}{0.862} \\
\hline & $>39$ years $n(\%)$ & 31 (48.4) & $30(50.0)$ & \\
\hline \multirow{2}{*}{ Marital status } & Married n (\%) & $56(87.5)$ & $43(71.7)$ & \multirow{2}{*}{0.028} \\
\hline & Unmarried n (\%) & $8(12.5)$ & $17(28.3)$ & \\
\hline \multirow{3}{*}{$\mathrm{BMI} \mathrm{kg} / \mathrm{m}^{2}$} & Mean \pm SD & $31.8 \pm 6.7$ & $31.8 \pm 6.0$ & $0.998^{\mathrm{a}}$ \\
\hline & Obese (BMI $\geq 30)$ n (\%) & $34(53.1)$ & $36(60.0)$ & \multirow{2}{*}{0.440} \\
\hline & Non-obese $(\mathrm{BMl}<30) \mathrm{n}(\%)$ & $30(46.9)$ & $24(40.0)$ & \\
\hline \multirow{2}{*}{ 25-OH-vitamin D nmol/L } & Mean \pm SD & $28.70 \pm 24.46$ & $37.19 \pm 26.46$ & $0.067^{b}$ \\
\hline & Low D3 n (\%) & $57(89.1)$ & 47 (78.3) & 0.105 \\
\hline \multirow{2}{*}{ Corrected calcium mmol/L } & Mean \pm SD & $2.2 \pm 0.13$ & $2.2 \pm 0.20$ & $0.649^{\mathrm{a}}$ \\
\hline & Low corrected calcium n (\%) & $16(25.0)$ & $13(21.7)$ & 0.661 \\
\hline \multirow{2}{*}{ PTH pmol/L } & Mean \pm SD & $5.64 \pm 2.60$ & $5.80 \pm 2.96$ & $0.747^{\mathrm{a}}$ \\
\hline & High PTH n (\%) & $23(35.9)$ & $20(33.3)$ & 0.761 \\
\hline Phosphorus mmol/L & Mean \pm SD & $1.51 \pm 0.26$ & $1.55 \pm 0.43$ & $0.641^{b}$ \\
\hline ALP $\mu \mathrm{kat} / \mathrm{L}$ & Mean \pm SD & $1.45 \pm 0.56$ & $1.41 \pm 0.50$ & $0.550^{\mathrm{b}}$ \\
\hline \multicolumn{5}{|c|}{ TABLE 1: General characteristics of the women in the niqab and hijab groups. } \\
\hline \multicolumn{5}{|c|}{ ALP: alkaline phosphatase; BMl: body mass index; PTH: parathyroid hormone; SD: standard deviation } \\
\hline
\end{tabular}

There was a significant difference in marital status between the niqab and hijab group; there were more married women in both groups and more in the niqab group than the hijab group. The marital status of women in both groups had no significant difference in the frequency of low 25-OH-vitamin D. Unmarried women who wore the niqab had a 10-fold risk of having high PTH compared to women who wear hijab.

Tables 2, 3 elucidate the effect of different factors (e.g., age, marital status, and weight) on vitamin D3 metabolic parameters as categorical variables and continuous variables, respectively. BMI did not affect the distribution of cases between groups; the sample was nearly weight-matched. The only significant difference was seen in non-obese (lean) women in the niqab group who have an odds ratio of 7.0. Non-obese niqab wearers were seven times more prone to have hypovitaminosis D3 than non-obese hijab wearers. We found no significant difference between the 25-OH-vitamin D levels in the two groups. We noticed more women with hypovitaminosis D3 and lower mean 25-OH-vitamin D levels in the niqab group than women in the hijab group. This was evident in the lack of significant difference in the mean PTH and the number of women with niqab who had high PTH levels (i.e., 23 women with niqab had high PTH versus 20 women with hijab). 


\section{Cureus}

\begin{tabular}{|c|c|c|c|c|c|c|}
\hline \multicolumn{2}{|c|}{ Parameters of vitamin D3 metabolism } & Niqab group $(n=64)$ & Hijab group $(n=60)$ & OR & $95 \% \mathrm{Cl}$ & P-Value \\
\hline \multicolumn{7}{|l|}{ Low 25-OH-vitamin D } \\
\hline \multirow{2}{*}{ Age years $\mathrm{n}(\%)$} & $\leq 39$ & 30 (90.9) & 25 (83.3) & 2.00 & $0.435-9.205$ & 0.367 \\
\hline & $>39$ & 27 (87.1) & 22 (73.3) & 2.46 & $0.652-9.241$ & 0.176 \\
\hline \multirow{2}{*}{ Marital status n (\%) } & Married & 49 (87.5) & 32 (74.4) & 2.41 & $0.84-6.856$ & 0.094 \\
\hline & Unmarried & $8(100.0)$ & 15 (88.2) & 1.13 & 0.953-1.348 & 0.312 \\
\hline \multirow{2}{*}{ BMI n (\%) ${ }^{a}$} & Obese & $29(85.3)$ & 31 (86.1) & 0.94 & $0.245-3.569$ & 0.922 \\
\hline & Non-obese & 28 (93.3) & $16(66.7)$ & 7.00 & $1.322-37.066$ & 0.012 \\
\hline \multicolumn{7}{|l|}{ Low corrected calcium } \\
\hline \multirow{2}{*}{ Age years $\mathrm{n}(\%)$} & $\leq 39$ & $9(27.3)$ & $7(23.3)$ & 1.32 & $0.394-3.858$ & 0.720 \\
\hline & $>39$ & $7(22.6)$ & $6(20.0)$ & 1.17 & $0.342-3.985$ & 0.806 \\
\hline \multirow{2}{*}{ Marital status $\mathrm{n}(\%)$} & Married & $12(21.4)$ & $8(18.6)$ & 1.19 & $0.440-3.239$ & 0.729 \\
\hline & Unmarried & $4(50.0)$ & $5(29.4)$ & 2.40 & 0.423-13.601 & 0.317 \\
\hline \multirow{2}{*}{ BMI n (\%) } & Obese & $7(20.6)$ & $7(19.4)$ & 1.07 & $0.333-3.466$ & 0.905 \\
\hline & Non-obese & $9(30.0)$ & $6(25.0)$ & 1.29 & $0.384-4.310$ & 0.684 \\
\hline \multicolumn{7}{|l|}{ High PIH } \\
\hline \multirow{2}{*}{ Age years $\mathrm{n}(\%)$} & $\leq 39$ & $15(45.5)$ & $11(36.7)$ & 1.44 & $0.524-3.954$ & 0.479 \\
\hline & $>39$ & $8(25.8)$ & $9(30.0)$ & 0.81 & $0.265-2.490$ & 0.715 \\
\hline \multirow{2}{*}{ Marital status $\mathrm{n}(\%)$} & Married & $16(28.6)$ & $13(30.2)$ & 0.923 & $0.386-2.207$ & 0.857 \\
\hline & Unmarried & $7(87.5)$ & $7(41.2)$ & 10.00 & $0.995-100.462$ & 0.030 \\
\hline \multirow{2}{*}{ BMI n (\%) ${ }^{a}$} & Obese & $14(41.2)$ & $11(30.6)$ & 1.59 & $0.594-4.258$ & 0.354 \\
\hline & Non-obese & $9(30.0)$ & $9(37.5)$ & 0.71 & $0.229-2.227$ & 0.561 \\
\hline
\end{tabular}

TABLE 2: Factors affecting the frequency of some vitamin D3 metabolic parameters between women in the niqab and hijab groups.

aThe obesity range includes $\mathrm{BMI} \geq 30 \mathrm{~kg} / \mathrm{m}^{2}$, and non-obesity includes $\mathrm{BMI}<30 \mathrm{~kg} / \mathrm{m}^{2}$

BMI: body mass index; Cl: confidence interval; OR: odds ratio; PTH: parathyroid hormone 


\section{Cureus}

\begin{tabular}{|c|c|c|c|c|c|}
\hline \multicolumn{3}{|c|}{ Metabolic parameters of vitamin D3 } & Niqab group Mean \pm SD & Hijab group Mean \pm SD & P-Value \\
\hline \multirow{6}{*}{ Low 25-OH-vitamin D nmol/L } & \multirow{2}{*}{ Age } & $\leq 39$ years & $26.21 \pm 16.22$ & $34.45 \pm 26.46$ & $0.386^{\mathrm{a}}$ \\
\hline & & $>39$ years & $31.70 \pm 30.95$ & $40.19 \pm 26.71$ & $0.104^{\mathrm{a}}$ \\
\hline & \multirow{2}{*}{ Marital status } & Married & $27.21 \pm 25.46$ & $41.43 \pm 27.96$ & $0.003^{\mathrm{a}}$ \\
\hline & & Unmarried & $39.44 \pm 8.24$ & $26.46 \pm 18.97$ & $0.023^{\mathrm{a}}$ \\
\hline & \multirow{2}{*}{$\mathrm{BMI}^{\mathrm{C}}$} & Obese & $30.45 \pm 5.24$ & $33.20 \pm 3.74$ & $0.202^{\mathrm{a}}$ \\
\hline & & Non-obese & $26.96 \pm 13.98$ & $43.18 \pm 31.70$ & $0.015^{\mathrm{b}}$ \\
\hline \multirow{6}{*}{ Low corrected calcium mmol/L } & \multirow{2}{*}{ Age } & $\leq 39$ years & $2.18 \pm 0.10$ & $2.20 \pm 0.23$ & $0.405^{\mathrm{a}}$ \\
\hline & & $>39$ years & $2.23 \pm 0.13$ & $2.23 \pm 0.15$ & $0.729^{a}$ \\
\hline & \multirow{2}{*}{ Marital status } & Married & $2.20 \pm 0.10$ & $2.23 \pm 0.15$ & $0.527^{\mathrm{a}}$ \\
\hline & & Unmarried & $2.20 \pm 0.18$ & $2.6 \pm 0.25$ & $0.793^{\mathrm{a}}$ \\
\hline & \multirow{2}{*}{$\mathrm{BMI}^{\mathrm{C}}$} & Obese & $2.20 \pm 0.13$ & $2.23 \pm 0.18$ & $0.687^{b}$ \\
\hline & & Non-obese & $2.20 \pm 0.10$ & $2.2 \pm 0.20$ & $0.774^{\mathrm{a}}$ \\
\hline \multirow{6}{*}{ High PTH pmol/L } & \multirow{2}{*}{ Age } & $\leq 39$ years & $6.41 \pm 2.81$ & $5.69 \pm 3.00$ & $0.325^{\mathrm{b}}$ \\
\hline & & $>39$ years & $4.82 \pm 2.10$ & $5.91 \pm 2.95$ & $0.099^{b}$ \\
\hline & \multirow{2}{*}{ Marital status } & Married & $5.38 \pm 2.46$ & $5.72 \pm 2.74$ & $0.587^{\mathrm{a}}$ \\
\hline & & Unmarried & $7.46 \pm 2.99$ & $6.01 \pm 3.53$ & $0.308^{\mathrm{a}}$ \\
\hline & \multirow{2}{*}{$\mathrm{BMI}^{\mathrm{C}}$} & Obese & $6.06 \pm 2.90$ & $5.61 \pm 2.67$ & $0.496^{b}$ \\
\hline & & Non-obese & $5.16 \pm 2.15$ & $6.09 \pm 3.38$ & $0.224^{b}$ \\
\hline
\end{tabular}

TABLE 3: Factors affecting the mean of some parameters of vitamin D3 metabolism in women in the niqab and hijab groups.

${ }^{a}$ Mann-Whitney U-test; ${ }^{b_{t-t e s t}}{ }^{\mathrm{C}}$ The obesity range included $\mathrm{BMI} \geq 30 \mathrm{~kg} / \mathrm{m}^{2}$, and non-obesity range included $\mathrm{BMI}<30 \mathrm{~kg} / \mathrm{m}^{2}$

BMI: body mass index; PTH: parathyroid hormone; SD: standard deviation

The mean level and the total number of women with low corrected calcium, mean phosphorus, and mean ALP was not significantly different.

Table 4 presents the effect of age, marital status, and weight on various vitamin D metabolic markers in the niqab group only, and Table 5 lists categorical and continuous variables. There were no significant differences in these parameters in women of different ages and weights. Marital status did not affect the number of women wearing niqab with low $25-\mathrm{OH}$-vitamin $\mathrm{D}$ and corrected calcium. Unmarried women wearing niqab had significantly higher $25-\mathrm{OH}$-vitamin D levels than married women $(39.44 \mathrm{nmol} / \mathrm{L} \pm 8.24$ $\mathrm{nmol} / \mathrm{L}$ versus $27.21 \mathrm{nmol} / \mathrm{L} \pm 25.46 \mathrm{nmol} / \mathrm{L}$ ), yet both married and unmarried women had low $25-\mathrm{OH}-$ vitamin D levels. Unmarried women also had significantly higher PTH levels than married women wearing a niqab $(7.46 \mathrm{pmol} / \mathrm{L} \pm 2.99 \mathrm{pmol} / \mathrm{L}$ versus $5.38 \mathrm{pmol} / \mathrm{L} \pm 2.46 \mathrm{pmol} / \mathrm{L}$. Age did not affect 25 - $\mathrm{OH}$-vitamin $\mathrm{D}$ or corrected calcium; its significant effect was only on the PTH levels (i.e., the lower the age, the higher the PTH level). The PTH level of women aged 39 or younger was more than women older than $39(6.41 \mathrm{pmol} / \mathrm{L} \pm$ $2.81 \mathrm{pmol} / \mathrm{L}$ versus $4.82 \mathrm{pmol} / \mathrm{L} \pm 2.10 \mathrm{pmol} / \mathrm{L}$ ). 


\section{Cureus}

\begin{tabular}{|c|c|c|c|c|}
\hline \multicolumn{2}{|l|}{ Variables } & Low 25-OH-vitamin D & Low corrected calcium & High PTH \\
\hline \multirow{5}{*}{ Age } & $\leq 39$ years $\mathrm{n}(\%)$ & $30(90.9)$ & $9(27.3)$ & $15(45.5)$ \\
\hline & $>39$ years $\mathrm{n}(\%)$ & $27(87.1)$ & $7(22.6)$ & $8(25.8)$ \\
\hline & OR & 1.481 & 1.286 & 2.396 \\
\hline & $95 \% \mathrm{Cl}$ & $0.304-7.226$ & $0.412-4.013$ & $0.833-6.893$ \\
\hline & P-Value & 0.625 & 0.665 & 0.102 \\
\hline \multirow{5}{*}{ Marital status } & Married n (\%) & $49(87.5)$ & $12(21.4)$ & $16(28.6)$ \\
\hline & Unmarried n (\%) & $8(100.0)$ & $4(50.0)$ & $7(87.5)$ \\
\hline & OR & 0.875 & 0.273 & 0.057 \\
\hline & $95 \% \mathrm{Cl}$ & $0.793-0.966$ & $0.059-1.254$ & $0.006-0.502$ \\
\hline & P-Value & 0.289 & 0.081 & 0.001 \\
\hline \multirow{5}{*}{ BMI } & Obese $\left(\mathrm{BMI} \geq 30 \mathrm{~kg} / \mathrm{m}^{2}\right) \mathrm{n}(\%)$ & $29(85.3)$ & $7(20.6)$ & $14(41.2)$ \\
\hline & Non-obese $\left(\mathrm{BMI}<30 \mathrm{~kg} / \mathrm{m}^{2}\right) \mathrm{n}(\%)$ & $28(93.3)$ & $9(30.0)$ & $9(30.0)$ \\
\hline & OR & 0.414 & 0.605 & 1.633 \\
\hline & $95 \% \mathrm{Cl}$ & $0.074-2.314$ & $0.193-1.893$ & $0.579-4.609$ \\
\hline & P-Value & 0.304 & 0.386 & 0.352 \\
\hline
\end{tabular}

TABLE 4: Factors affecting the frequency of vitamin D3 metabolic parameters in women with niqab only.

BMI: body mass index; Cl: confidence interval; OR: odds ratio; PTH: parathyroid hormone

\begin{tabular}{|c|c|c|c|c|}
\hline \multicolumn{2}{|l|}{ Parameters } & 25-OH-vitamin $\mathrm{D}^{\mathrm{a}}$ & Corrected calcium $^{a}$ & PTH $^{\mathbf{a}}$ \\
\hline \multirow{3}{*}{ Age } & $\leq 39$ & $26.21 \pm 16.22$ & $2.18 \pm .10$ & $6.41 \pm 2.81$ \\
\hline & $>39$ & $31.70 \pm 30.95$ & $2.23 \pm 0.13$ & $4.82 \pm 2.10$ \\
\hline & P-Value & $0.696^{b}$ & $0.228^{\mathrm{C}}$ & $0.013^{\mathrm{C}}$ \\
\hline \multirow{3}{*}{ Marital status } & Married & $27.21 \pm 25.46$ & $2.20 \pm 0.10$ & $5.38 \pm 2.46$ \\
\hline & Unmarried & $39.44 \pm 8.24$ & $2.20 \pm 0.18$ & $7.46 \pm 2.99$ \\
\hline & P-Value & $0.012^{b}$ & $0.920^{C}$ & $0.022^{\mathrm{C}}$ \\
\hline \multirow{3}{*}{ BMI } & Obese & $30.45 \pm 5.24$ & $2.20 \pm 0.13$ & $6.06 \pm 2.90$ \\
\hline & Non-obese & $26.96 \pm 2.50$ & $2.20 \pm 0.10$ & $5.16 \pm 2.15$ \\
\hline & P-Value & $0.787^{b}$ & $0.458^{C}$ & $0.169^{c}$ \\
\hline \multicolumn{5}{|c|}{$\begin{array}{l}\text { TABLE 5: Factors affecting the mean of parameters of vitamin D3 metabolism in women we } \\
\text { niqab only. All variables are expressed as (mean } \pm \text { standard deviation). } \\
\text { aSI units of } 25-\mathrm{OH} \text {-vitamin D, corrected calcium, and PTH are nmol/L, mmol/L, and pmol/L, respectively; }{ }^{b} \text { Mann-Whitney U-test; }{ }^{\mathrm{C}} \mathrm{t}-\mathrm{test}\end{array}$} \\
\hline \multicolumn{5}{|c|}{ BMI: body mass index; 25-OH: 25-hydroxycholecalciferol; PTH: parathyroid hormone } \\
\hline
\end{tabular}

Figure $1 \mathrm{~A}$ presents the relationship between the $25-\mathrm{OH}$-vitamin D level and the PTH in both groups of 


\section{Cureus}

women. We found a significant inverse relationship between the two variables in both groups of women. The reduction in the level of 25-OH-vitamin D was accompanied by an increase in the level of PTH in both groups in a similar pattern (i.e., D3 $=34.97-1.1 \times \mathrm{PTH}$ in women with niqab, and D3 $=53.15-2.74 \times \mathrm{PTH}$ in women with hijab). Figure $1 B$ illustrates the relationship between $25-\mathrm{OH}$-vitamin D level and BMI in both groups of women. The distribution was unclear and lacked any significance in both groups. The 25-OHvitamin D increased with increasing BMI in women wearing niqab $(\mathrm{D} 3=19.82+0.28 \times \mathrm{BMI})$, while it decreased as the BMI increased in women wearing hijab (63.59 - $0.83 \times \mathrm{BMI})$.

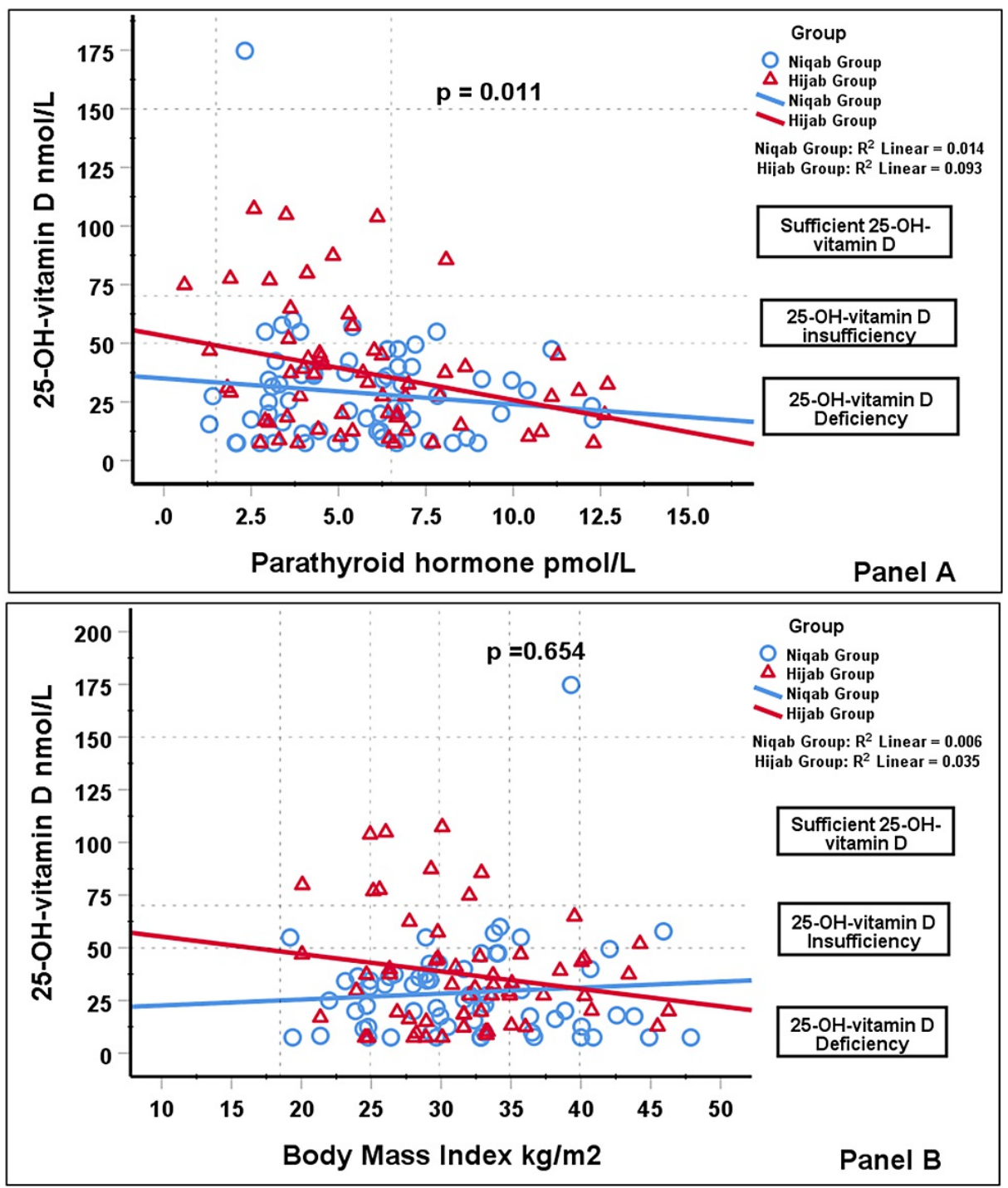

FIGURE 1: Panel A demonstrates the significant inverse linear relationship between the 25-OH-vitamin D with the different PTH levels for women wearing niqab and hijab. Panel B demonstrates the nonsignificant linear relationship between 25-OH-vitamin D at different BMI levels for women wearing niqab and hijab. The relationship was inverse in women with hijab, while it increased as the BMI increased, although no specific pattern can be deduced in women wearing niqab. Most women had either a deficient or insufficient level of 25-OH-vitamin D. There was one extreme $25-\mathrm{OH}$-vitamin $\mathrm{D}$ value for a woman with a niqab above the upper limit of the reference range. The dotted lines in the figure represent the different limits of the reference ranges of $25-\mathrm{OH}$ vitamin D, PTH, and BMI.

BMI: body mass index; PTH: parathyroid hormone; 25-OH-vitamin D: 25-hydroxycholecalciferol vitamin D 


\section{Discussion}

Although Basrah, with its tropical latitude $\left(30.5^{\circ} \mathrm{N}, 47.8^{\circ} \mathrm{E}\right)$, enjoys a sunny climate throughout the year [13], direct exposure to sunlight by the local population is limited due to high daytime temperatures, which may reach up to $50^{\circ} \mathrm{C}$ in summer. Most individuals stay indoors during the day with minimal sunlight exposure associated with low vitamin D levels among women.

The low sunlight exposure is a common problem in many Middle East countries with abundant sunlight. Previous reports attributed hypovitaminosis D to limited sunlight exposure, low vitamin D intake, indoor work environment, concealed dress styles that cover most of the body (including the face, head, and arms), parity, and the prevailing social norms that the women are home-bound and leave only when necessary, often with permission from the husband or guardian [1,3,14-16]. Subnormal serum 25-OH-vitamin D levels were found in women wearing coverings and long clothing that might have interfered with penetration of UVB radiation into the skin even when exposed to sunlight which affects the cutaneous synthesis of vitamin D3 [17]. Other studies suggested that the dress style was not the sole marker for hypovitaminosis D $[3,18,19]$.

Approximately $89 \%$ of women wearing a niqab in our cohort $(n=57)$ had hypovitaminosis D3 compared to $78 \%$ of women wearing hijab $(n=47)$. The relationship between the level of $25-\mathrm{OH}$-vitamin $\mathrm{D}$ and the dress style was not significant. Hypovitaminosis D in women wearing the niqab or hijab was consistent with previous studies $[1,3,6,16,20]$. Batieha et al. found that the relation between hypovitaminosis D and exposed skin area was close to scientific significance. However, women wearing hijab and niqab did not differ significantly in their mean serum 25-OH-vitamin D levels [3].

There was no significant difference in PTH levels for either dress style, and we found no significant difference in the number of women with high PTH by dress style. All changes encountered initially are insignificant, regardless of dress style. Still, more women with corresponding changes in 25-OH-vitamin D and PTH in the niqab group were encountered. Similar data for the effect of low 25-OH-vitamin D and PTH were reported from many Middle Eastern countries with mean serum 25-OH-vitamin D lower in the niqab group compared to the hijab group, in whom indoor employment may play a role. Many studies adopted the lowest conservative ranges for vitamin $\mathrm{D} 3$, with a higher set point or physiologic adaptation of vitamin $\mathrm{D}$, which may upregulate PTH $[1,3,21,22]$. Other studies also reported a non-significant relationship between vitamin D and PTH $[7,11,18,23,24]$.

The significant inverse relationship between 25-OH-vitamin D and PTH in Figure $1 \mathrm{~A}$ indicated hypovitaminosis D in both groups. The result was similar to those reported in two Jordanian studies $[3,4]$. The cut-off values of $25-\mathrm{OH}$-vitamin $\mathrm{D}$, which mark the deficiency and insufficiency status, overlap [25]. It had been proposed that 30 to $125 \mathrm{nmol} / \mathrm{L}$ of $25-\mathrm{OH}$-vitamin D is required to maintain normal PTH levels, with most studies reporting values of approximately 75 to $80 \mathrm{nmol} / \mathrm{L}$ such as Al-Mogbel et al. [21], Grant et al. [25], and Wat et al. [26]. The biochemical assays to estimate 25-OH-vitamin D and PTH affect the correlation between the two variables and other variables, including latitude, diet, race, age, and gender [27].

Although 25-OH-vitamin D levels were markedly reduced, PTH levels were not increased in most women, similar to findings reported by Haarburger et al. They suggested that 25-OH-vitamin D measurements should be requested when hypovitaminosis D is clinically suspected, irrespective of calcium and PTH results. The subnormal 25-OH-vitamin D levels were not always related to hypocalcemia or a rise in PTH levels [24]. The elevated PTH in the presence of normocalcemia might reflect a subclinical or mildly clinical hypovitaminosis D $[5,18,24]$.

Hypocalcemia stimulates PTH secretion, which activates vitamin D synthesis. Vitamin D and PTH production enhance renal calcium reabsorption and calcium mobilization by bone resorption. However, hypercalcemia promotes a reduction in PTH secretion and decreases vitamin D synthesis and calcium mobilization. Hypercalcemia also stimulates parafollicular cells in the thyroid to secrete calcitonin, inhibit calcium mobilization from the bone, stimulate the excretion of calcium and phosphorous, and maintain calcium within normal levels [28].

We found a 10-fold risk for unmarried women wearing niqab to have high PTH than unmarried women wearing hijab. This observation was limited to seven women from each group. Although a statistical significance was achieved, we could not confirm it on a larger scale during our study, especially given the odds ratio of unmarried women with low 25-OH-vitamin D levels, which is the main contributing factor for high PTH. Batieha et al. concluded that married women were significantly less likely to have lower vitamin D levels than unmarried women, wearing any dress style (niqab, hijab, or western style) based on their higher sample size (3,624 married women versus 644 unmarried women) [3]. Marital status was not the sole determinant of vitamin D status.

Women's age did not affect PTH level. Batieha et al. concluded that older women had significantly higher PTH than men; however, they did not evaluate PTH in subgroups of women with different dress styles [3]. 
During the initial evaluation, the groups were weight-matched, with no significant difference between both groups (Table 1). However, during subgroup analysis, the non-obese had significantly more risk (i.e., seven times) of having hypovitaminosis $\mathrm{D}$, which is more evident in lean women with niqab than women in hijab ( $26.96 \pm 13.98 \mathrm{nmol} / \mathrm{L}$ versus $43.18 \pm 31.70 \mathrm{nmol} / \mathrm{L}$, respectively). Overall, $84 \%$ of women had hypovitaminosis D3 (57 women with niqab, 47 women with hijab). Both groups had mean vitamin D levels that fell within the range of severe vitamin D deficiency. Figure $1 B$ showed the pattern of decreasing $25-\mathrm{OH}-$ vitamin D levels as the BMI increased in the hijab group, while for the niqab group, the pattern was different.

Other studies have compared the effect of weight or BMI on vitamin D3 and confirmed that the higher the BMI, the lower the vitamin D3 [4,6,14,29,30]. Still, these studies had higher ranges of vitamin D3 levels above the reference levels. Women wearing the niqab are less likely to participate in outdoor activities than those in the other studies.

The mean BMI in both groups was in the obese range. Abundant adipose tissue limits the bioavailability of 25-OH-vitamin D [14]. Therefore, the association between hypovitaminosis D and obesity remains inconclusive. The results indicate the presence of other contributory factors for hypovitaminosis D in lean women from both groups with a more complex relationship than vitamin D bioavailability and uptake.

Despite low 25-OH-vitamin D levels among the participants, our study showed that corrected serum calcium, phosphorus, and ALP levels were within the normal range in approximately $77 \%$ of women $(n=95)$ for serum calcium and all enrolled women for serum phosphorus and ALP. This finding might be attributed to compensatory high PTH levels.

We found no significant difference between the two groups in the mean or total incidence of low corrected calcium, phosphorus, and ALP, which are indicators of bone turnover. Although most of the cohort from both groups had low 25-OH-vitamin D levels, $25 \%$ of the niqab group $(n=16)$ had low corrected calcium compared to approximately $22 \%$ of the hijab group $(n=13)$, and there was no significant difference between the groups.

The mean corrected calcium in both groups was within the reference ranges with no significant relationship to the dress style, similar to studies reported in neighboring countries [14,18]. Other studies showed lower serum calcium levels associated with dress style [2,23], with a significant positive correlation between 25$\mathrm{OH}$-vitamin D and ionized calcium [20]. In most cases, the finding of normal serum biochemical parameters was interesting and alarming, as many osteomalacia and osteoporosis cases could be missed if serum 25$\mathrm{OH}$-vitamin D were not measured.

We chose age-matched groups of premenopausal women to overcome the possible physiological anabolic estrogen action on bones in both groups regardless of the dress style for this study. However, the study had many limitations. The small size may not represent the burden of hypovitaminosis D in these women, which was influenced by the total number of FDEMC attendees who wore the niqab, which was small. We did not have an accurate tool to measure daily calcium and vitamin D intake. The seasonal variation in sun exposure behavior was not evaluated. The effect on bone density and turnover markers was not tested due to its unnecessary cost, and there were no relevant indications. We did not have any reliable data about social norms or the women's actual outdoor activities concerning the time spent indoors or outdoors. We did not study the social barriers that influence women to be home-bound most of the time. Despite these limitations, the seemingly homogeneous population in the present study was well documented in demographic and biochemical measurements.

\section{Conclusions}

Clothing is an effective blocker to sun exposure and thus contributes to vitamin D synthesis and status. Given the low comparative exposed skin areas, wearing the niqab or hijab was not associated with significant differences in vitamin D3 metabolic parameters. The majority of study participants in both groups had hypovitaminosis D3 at presentation, albeit asymptomatic. Young unmarried women wearing niqab had significantly higher PTH levels in comparison to unmarried women wearing hijab. These women also showed significantly higher 25-OH-vitamin D levels, although it was deficient compared to married women wearing niqab or hijab. Healthcare providers should advise these women of precautionary measures to increase their vitamin D3 levels through culturally and religiously appropriate alternative mechanisms.

\section{Additional Information}

\section{Disclosures}

Human subjects: Consent was obtained or waived by all participants in this study. FDEMC Research Committee issued approval NA. Animal subjects: All authors have confirmed that this study did not involve animal subjects or tissue. Conflicts of interest: In compliance with the ICMJE uniform disclosure form, all authors declare the following: Payment/services info: All authors have declared that no financial support was received from any organization for the submitted work. Financial relationships: All authors have declared that they have no financial relationships at present or within the previous three years with any 
organizations that might have an interest in the submitted work. Other relationships: All authors have declared that there are no other relationships or activities that could appear to have influenced the submitted work.

\section{Acknowledgements}

The authors thank all the women who agreed to participate in the study.

\section{References}

1. Mishal AA: Effects of different dress styles on vitamin D levels in healthy young Jordanian women . Osteoporos Int. 2001, 12:931-5. 10.1007/s001980170021

2. Mallah EM, Hamad MF, Elmanaseer MA, Oinna NA, Idkaidek NM, Arafat TA, Matalka KZ: Plasma concentrations of 25-hydroxyvitamin D among Jordanians: effect of biological and habitual factors on vitamin D status. BMC Clin Pathol. 2011, 11:8. 10.1186/1472-6890-11-8

3. Batieha A, Khader Y, Jaddou H, et al.: Vitamin D status in Jordan: dress style and gender discrepancies . Ann Nutr Metab. 2011, 58:10-8. 10.1159/000323097

4. Hyari M, Abu-Romman H: Vitamin D status among patients attending Hussein Medical Center for Diabetes in Jordan. J R Med Sci. 2013, 20:6-13. 10.12816/0001543

5. Elsammak MY, Al-Wossaibi AA, Al-Howeish A, Alsaeed J: High prevalence of vitamin D deficiency in the sunny Eastern region of Saudi Arabia: a hospital-based study. East Mediterr Health J. 2011, 17:317-22.

6. El-Khateeb M, Khader Y, Batieha A, et al.: Vitamin D deficiency and associated factors in Jordan . SAGE Open Med. 2019, 7:1-6. 10.1177/2050312119876151

7. Al-Yatama FI, AlOtaibi F, Al-Bader MD, Al-Shoumer KA: The effect of clothing on vitamin D status, bone turnover markers, and bone mineral density in young Kuwaiti females. Int J Endocrinol. 2019, 2019:6794837. 10.1155/2019/6794837

8. Chakhtoura M, Rahme M, Chamoun N, El-Hajj Fuleihan G: Vitamin D in the Middle East and North Africa . Bone Rep. 2018, 8:135-46. 10.1016/j.bonr.2018.03.004

9. Bassil D, Rahme M, Hoteit M, Fuleihan Gel-H: Hypovitaminosis D in the Middle East and North Africa: prevalence, risk factors and impact on outcomes. Dermatoendocrinol. 2013, 5:274-98. 10.4161/derm.25111

10. Al-Horani H, Abu Dayyih W, Mallah E, Hamad M, Mima M, Awad R, Arafat T: Nationality, gender, age, and body mass index influences on vitamin $\mathrm{D}$ concentration among elderly patients and young Iraqi and Jordanian in Jordan. Biochem Res Int. 2016, 2016:8920503. 10.1155/2016/8920503

11. Al-Alyani H, Al-Turki HA, Al-Essa ON, Alani FM, Sadat-Ali M: Vitamin D deficiency in Saudi Arabians: a reality or simply hype: a meta-analysis (2008-2015). J Family Community Med. 2018, 25:1-4. 10.4103/jfcm.JFCM_73_17

12. Judistiani RTD, Nirmala SA, Rahmawati M, et al.: Optimizing ultraviolet B radiation exposure to prevent vitamin D deficiency among pregnant women in the tropical zone: report from cohort study on vitamin D status and its impact during pregnancy in Indonesia. BMC Pregnancy Childbirth. 2019, 19:209. 10.1186/s12884-019-2306-7

13. WorldWeatherOnline.com. 2020. Basra monthly climate averages. (2020). Accessed: August 27, 2020: https://www.worldweatheronline.com/basra-weather-averages/al-basrah/iq.aspx.

14. Buyukuslu N, Esin K, Hizli H, Sunal N, Yigit P, Garipagaoglu M: Clothing preference affects vitamin D status of young women. Nutr Res. 2014, 34:688-93. 10.1016/i.nutres.2014.07.012

15. Güler T, Sivas F, Başkan BM, Günesen O, Alemdaroğlu E, Ozoran K: The effect of outfitting style on bone mineral density. Rheumatol Int. 2007, 27:723-7. 10.1007/s00296-006-0297-y

16. Botros RM, Sabry IM, Abdelbaky RS, Eid YM, Nasr MS, Hendawy LM: Vitamin D deficiency among healthy Egyptian females. Endocrinol Nutr. 2015, 62:314-21. 10.1016/j.endonu.2015.03.010

17. Holick MF, Chen TC: Vitamin D deficiency: a worldwide problem with health consequences . Am J Clin Nutr. 2008, 87:1080S-6S. 10.1093/ajen/87.4.1080S

18. Al Attia HM, Ibrahim MA: The high prevalence of vitamin D inadequacy and dress style of women in the sunny UAE. Arch Osteoporos. 2012, 7:307-10. 10.1007/s11657-012-0104-1

19. Islam MZ, Akhtaruzzaman M, Lamberg-Allardt C: Hypovitaminosis D is common in both veiled and nonveiled Bangladeshi women. Asia Pac J Clin Nutr. 2006, 15:81-7.

20. Mousa SG, Ismail SM, Mohamed NAE, Hassan OAA: Measurement of serum vitamin D25 level in normal Egyptian population. Clin Med Diagn. 2018, 8:63-8

21. Al-Mogbel ES: Vitamin D status among adult Saudi females visiting primary health care clinics . Int J Health Sci (Qassim). 2012, 6:116-26. 10.12816/0005987

22. AlFaris NA, AlKehayez NM, AlMushawah FI, AlNaeem AN, AlAmri ND, AlMudawah ES: Vitamin D Deficiency and Associated Risk Factors in Women from Riyadh, Saudi Arabia. Sci Rep. 2019, 9:20371. 10.1038/s41598-019-56830-z

23. Mahmood S, Rahman M, Biswas SK, et al.: Vitamin D and parathyroid hormone status in female garment workers: a case-control study in Bangladesh. Biomed Res Int. 2017, 2017:4105375. 10.1155/2017/4105375

24. Haarburger D, Hoffman M, Erasmus RT, Pillay TS: Relationship between vitamin D, calcium and parathyroid hormone in Cape Town. J Clin Pathol. 2009, 62:567-9. 10.1136/jcp.2008.062877

25. Grant WB, Holick MF: Benefits and requirements of vitamin D for optimal health: a review . Altern Med Rev. 2005, 10:94-111.

26. Wat WZ, Leung JY, Tam S, Kung AW: Prevalence and impact of vitamin D insufficiency in southern Chinese adults. Ann Nutr Metab. 2007, 51:59-64. 10.1159/000100822

27. Sai AJ, Walters RW, Fang X, Gallagher JC: Relationship between vitamin D, parathyroid hormone, and bone health. J Clin Endocrinol Metab. 2011, 96:E436-46. 10.1210/jc.2010-1886

28. Gil Á, Plaza-Diaz J, Mesa MD: Vitamin D: classic and novel actions. Ann Nutr Metab. 2018, 72:87-95. 10.1159/000486536

29. Nimri LF: Vitamin D status of female UAE college students and associated risk factors . J Public Health (Oxf). 


\section{Cureus}

2018, 40:e284-90. 10.1093/pubmed/fdy009

30. Zainel AAL, Qotba H, Al Nuaimi A, Syed M: Vitamin D status among adults (18-65 years old) attending primary healthcare centres in Qatar: a cross-sectional analysis of the Electronic Medical Records for the year 2017. BMJ Open. 2019, 9:e029334. 10.1136/bmjopen-2019-029334 